\title{
Qualidade de solo em áreas de cambissolo com diferentes manejos de pastagem ${ }^{1}$
}

\section{Soil quality in areas of inceptisol with different grassland management}

\author{
Rogério Resende Martins Ferreira ${ }^{2}$; Bruno Vieira Maciel $^{3}$; Anna Ignes de Sousa \\ Braga Carneiro Lemes ${ }^{3}$; Thadeu Rodrigues de Melo ${ }^{3}$; João Tavares Filho ${ }^{4 *}$
}

\section{Resumo}

Atualmente, busca-se nas atividades agrosilvopastoris a obtenção do maior retorno dos investimentos com equilíbrio social e sem degradar o meio ambiente. O objetivo deste trabalho foi avaliar a qualidade física e química de um Cambissolo, após 30 anos sob dois manejos de pastagens. O trabalho foi realizado em uma microbacia situada na Bacia do Alto Rio Grande (MG), em dois tipos de manejos de pastagem extensiva comuns na região: pastagem nativa sem queimada anual e pastagem nativa manejada com queimada anual, e em uma área de reserva legal que serviu de referência. Nessas áreas foram analisados: $\mathrm{CTC}_{\mathrm{pH} 7,0}$, matéria orgânica, densidade e porosidade do solo. De acordo com os resultados obtidos concluiu-se que os valores de densidade do solo, matéria orgânica, capacidade de troca de cátions e macro porosidade não diferiram na camada de solo analisada $(0-10 \mathrm{~cm})$ nos dois manejos estudados. Os polígonos formados no gráfico radial, comparando a área referência com os dois manejos estudados, são de magnitude e formato diferentes ao formado pelos valores de referência, indicando que o manejo sem queimadas anuais deve ser melhorado em relação à densidade do solo; já o manejo com queimadas anuais deve ser melhorado em relação à densidade, matéria orgânica, capacidade de troca de cátions e macroporosidade do solo.

Palavras-chave: Atributos físicos, atributos químicos, degradação do solo

\begin{abstract}
Currently, we seek to agronomy, forestry and pastoral activities to achieve the greatest return on investment with social equity, without degrading the environment. The objective of this study was to evaluate the physical and chemical quality of a Inceptisol after 30 years under two grazing managements. The study was conducted in a watershed located in the Upper Rio Grande (MG) in two types of extensive grazing managements common in the region: native pasture without burning native pasture and annual managed with annual burning, and a legal reserve area used as a reference. These areas were analyzed: $\mathrm{CTC}_{\mathrm{pH} 7,0}$, organic matter, soil density and porosity. According to the results obtained it was concluded that the values of bulk density, organic matter, cation exchange capacity and macro porosity did not differ in the analyzed soil layer $(0-10 \mathrm{~cm})$ in two management studies. The polygons formed in the radial graph, comparing the reference area with the two management studies, are of different magnitude and the shape formed by the reference values, indicating that the annual burning without management should be improved in relation to the density of the soil, whereas the management with annual fires should be improved in relation to the density, organic matter, cation exchange capacity and soil macroporosity.
\end{abstract}

Key words: Physical properties, chemical properties, soil degradation

\footnotetext{
${ }^{1}$ Trabalho apresentado sob a forma de Poster na Reunião Brasileira de Manejo e Conservação de Solo e Água, Terezina, PI.

${ }^{2}$ Eng $^{\circ}$ Agr $^{\circ}$ Dr., Projeto Maria de Barro/Recuperação Ambiental, Nazareno, MG. E-mail: rogerioferreir@yahoo.com.br

${ }^{3}$ Discente(s) do Curso de Agronomia da Universidade Estadual de Londrina, UEL, Cx Postal 6001, 86051-990, Londrina, PR. Bolsistas PIBIC e Fundação Araucária. E-mail: brunov_m@hotmail.com; anna_ignes@msn.com; thadeurodrigues@hotmail.com

${ }^{4}$ Prof. Dr. Associado C, Dept ${ }^{\circ}$ de Agronomia, UEL, Londrina, PR. E-mail: tavares@uel.br

* Autor para correspondência
} 
A necessidade crescente de aumento da produção agrícola tem provocado um uso intenso dos solos pelas atividades agrícolas, com alteração de seu equilíbrio natural e modificação de suas propriedades físicas, químicas e biológicas. As modificações serão tanto mais acentuadas quanto maior for a degradação provocada pelo sistema de manejo adotado, de forma que atualmente buscase nas atividades agrosilvipastoris, a obtenção do maior retorno dos investimentos com equilíbrio social sem provocar impacto sobre o meio ambiente (TAVARES FILHO; FERREIRA; FERREIRA, 2011)

$\mathrm{Na}$ bacia Alto Rio Grande (MG), município de Nazareno, predomina exploração agropecuária de pastagens nativas extensivas sobre Cambissolos derivados de rocha pelítica pobre, os quais têm uma ocorrência expressiva nessa região (31\% da área ocupada com as unidades de solo do Município), e apresentam naturalmente limitações à sua utilização agrícola por serem pobres quimicamente e apresentarem alta susceptibilidade à erosão (FERREIRA et al., 2010).

Independente dos aspectos expostos anteriormente, uma prática comum utilizada na região é a queima das pastagens nativas, expondo ainda mais esses solos no início das chuvas e agravando os problemas de erosão (HORTA, 2006). A queima de restos culturais sobre o solo, seguida ou não de preparo do mesmo, pode aumentar sua densidade, causar reduções em sua macroporosidade e na água disponível, além de diminuir o tempo e a profundidade de seu umedecimento (HERINGER et al., 2002; JACQUES, 2003; FERREIRA et al., 2010). Além disso, pode reduzir o teor de matéria orgânica, considerado um atributo chave já que apresenta papel no fornecimento de nutrientes e na melhoria das propriedades físico-hidricas e químicas do solo (FERNANDEZ; CABANEIRO, CARBALLAS, 1997; HERINGER et al., 2002; JACQUES, 2003; FERREIRA et al., 2010; TAVARES FILHO; FERREIRA; FERREIRA, 2011). Assim, o objetivo deste trabalho foi avaliar a qualidade física e química de um Cambissolo, após 30 anos sob dois manejos de pastagens.

O estudo foi realizado em áreas de pastagem extensivas, sobre Cambissolos originários de rochas pelíticas e de quartzito (HORTA, 2006), inseridos na superfície cristalina do Alto Rio Grande, município de Nazareno (MG) cuja posição geográfica é $21^{\circ} 22^{\prime}$ de latitude sul e $44^{\circ} 61^{\prime}$ de longitude oeste e altitude média de 935 m. Nessa região, a pecuária leiteira sempre se destacou, sendo a queima das pastagens nativas uma prática comum.

Foram selecionadas para o trabalho duas áreas próximas, a primeira com 12,32 ha e a segunda com 13,08 ha, ambas sobre Cambissolo com declive médio de $0,17 \mathrm{~m} \mathrm{~m}^{-1}$. O manejo da área 1 compreende pastagem nativa manejada sem queimada anual (PN) com produção de bovinocultura extensiva (1,1 UA ha-1), e o rebanho não é rotacionado (não há piquetes). $\mathrm{O}$ pasto não é tombado e não recebe nenhum cuidado especial (físico e/ou químico) há pelo menos 25 anos; e o manejo da área 2 compreende pastagem nativa manejada queimada anual (PQ) com produção de bovinocultura extensiva (0,9 UA ha-1), e o rebanho não é rotacionado (não há piquetes). $\mathrm{O}$ pasto não é tombado e não recebe nenhum cuidado especial (físico e/ou químico) há pelo menos 22 anos e faz uso de queimadas anuais sempre no mês de setembro.

Em cada área foram coletadas 30 amostras deformadas e indeformadas (anel volumétrico de $50,26 \mathrm{~cm}^{3}$ ) de solo de forma inteiramente casualizada e que cobrissem a área toda, na camada de $0-10$ $\mathrm{cm}$ para determinar a textura do solo, a densidade de partículas pelo método do álcool etílico, a $\mathrm{CTC}_{\mathrm{pH} 7,0}$, a matéria orgânica (MO), a densidade (Ds) e porosidade do solo (macro e microporosidade pelo método da mesa de tensão), segundo EMBRAPA (1997). Optou-se pela coleta de solo entre 0-10 cm, pois, segundo Heringer et al. (2002), não são observados efeitos da queimada no longo prazo a mais de $10 \mathrm{~cm}$ de profundidade no solo.

Os resultados médios obtidos (média de 30 
amostras) dos diferentes atributos de solo analisados para a profundidade de $0-10 \mathrm{~cm}$ para os dois manejos foram comparados pelo teste $t$-Student no nível de $5 \%$ de probabilidade. Para comparar a qualidade do solo de forma integrada sob os diferentes manejo, seguiu-se o procedimento apresentado por Costa, Goedert e Sousa (2006), e adotaram-se valores referenciais com índice $100 \%$ para os seguintes atributos: matéria orgânica, densidade e porosidade do solo (porosidade total e macroporosidade) e a capacidade de troca de cátions.

Verifica-se (Figura 1), que os valores de $\mathrm{CTC}_{\mathrm{pH} 7,0}$ do solo são baixos nos dois manejos estudados, sem diferença significativa entre eles. $\mathrm{O}$ manejo PQ apresentou os menores valores médios absolutos de $\mathrm{CTC}_{\mathrm{pH} 7,0}$, contrastando com as observações em que a queimada pode corrigir o solo e aumentar a oferta de nutrientes deste (SCHACHT et al., 1996).
Segundo Fernandez, Cabaneiro e Carballas (1997), esse "aumento" de nutrientes (NH4, P, Ca, Mg, e K) e $\mathrm{pH}$, tende a ocorrer nos primeiros momentos após a queimada, provavelmente devido ao efeito das cinzas, e tende a diminuir ou estabilizar próximo aos níveis anteriores à queima com o passar dos meses.

Quanto ao teor de MO (Figura 1), os dois manejos estudados foram caracterizados por altos intervalos de confiança, sem diferença significativa entre si. O manejo PQ apresentou os menores valores médios absolutos de MO. Esse resultado esta em acordo com Heringer et al. (2002), os quais relataram que o resultado da queimada no longo prazo é o decréscimo do teor de matéria orgânica do solo, não sendo observados efeitos a mais de $10 \mathrm{~cm}$ de profundidade, pois, a queimada aumenta a temperatura do solo somente na superfície do mesmo (NEVES; MIRANDA, 1996).

Figura 1. Valores médios e barra de erro que representa o desvio padrão $(n=30)$ da densidade do solo (Ds), capacidade de troca de cátions (CTC), macro (Ma) e microporosidade (Mi) e matéria orgânica (MO) de Cambissolo sob diferentes manejos (área de preservação permanente (referência), pastagem nativa sem queima anual (PN) e com queima anual (PQ)) para a profundidade de $0-10 \mathrm{~cm}$. A Comparação de médias feita pelo teste $t$-Sudent $(\mathrm{p}=0,05)$.

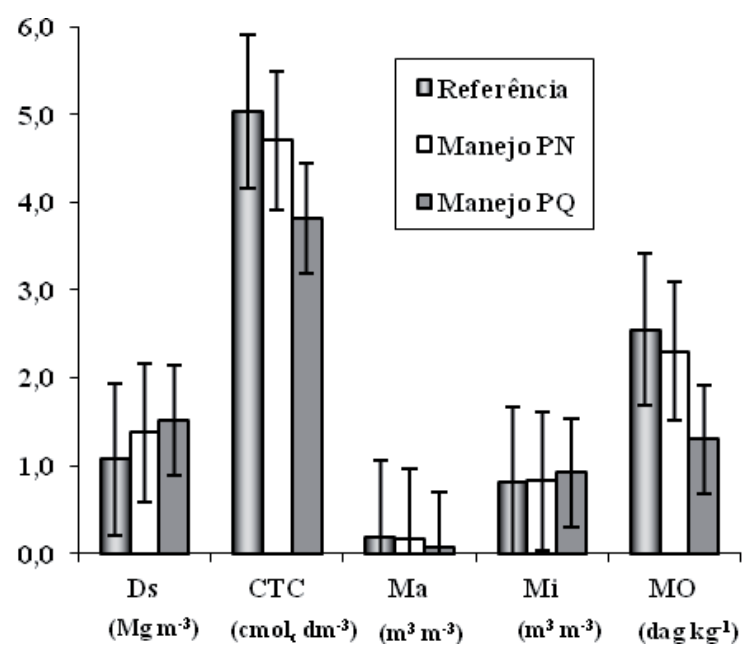

Fonte: Elaboração dos autores. 
Em relação aos resultados de Ds, macro e microporosidade (figura 1), verifica-se que os manejos PN e PQ não diferem entre si. O manejo PQ apresentou maiores valores médios absolutos de Ds e Microporosidade e menores valores de macroporosidade. Esses resultados estão em acordo com Ferreira et al. (2010) e ressaltando a sensibilidade do solo à ação do pisoteio dos animais ao longo dos anos nesse solo, pois, segundo Cohron (1972), os bovinos exercem em média, uma pressão de $0,17 \mathrm{MPa}$ por casco, podendo atingir uma penetração do solo da ordem de $12 \mathrm{~cm}$.

Visando comparar a qualidade dos dois manejos de pastagens extensivas sob Cambissolo estudados, a figura 2 apresenta o gráfico radial para os valores da Ds, da macro e microporosidade, do teor de $\mathrm{MO}$ e da $\mathrm{CTC}_{\mathrm{pH} 7,0}$, obtidos para a camada de 0 $10 \mathrm{~cm}$. Verifica-se que os valores de Ds estão acima e os valores de MO e CTC abaixo do valor de referência para os dois sistemas estudados, e ocorre uma melhor porosidade para o manejo PN e pior para o manejo PQ. Além disso, comparandose os polígonos formados, verifica-se que são de magnitude e formato diferentes ao formado pelos valores de referência, indicando que os manejos adotados podem ser melhorados, buscando melhor qualidade de solo.

Figura 2. Diagrama comparativo da qualidade dos sistemas de manejo de pastagens extensivas (PN -sem queima anual e PQ - com queima anual) sob Cambissolo, considerando-se os valores obtidos para a camada de $0-10 \mathrm{~cm}$ da densidade do solo (Ds), da capacidade de troca de cátions (CTC), da macro (Ma) e microporosidade (Mi) e do teor de matéria orgânica (MO).

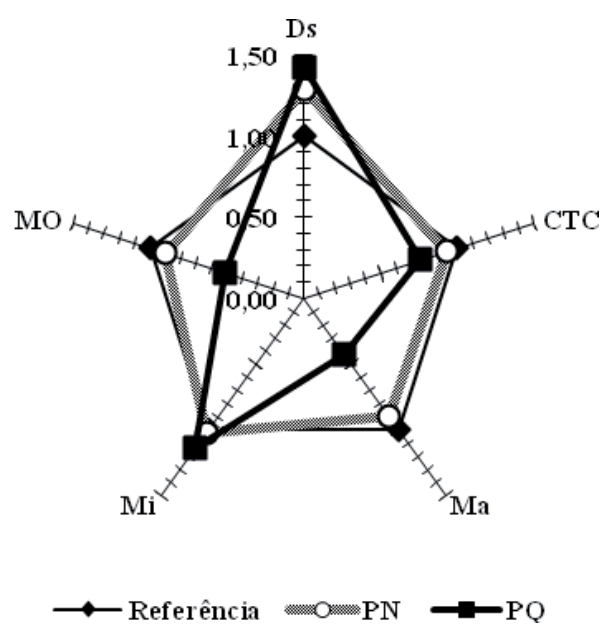

Fonte: Elaboração dos autores.

Dessa forma, considerando que a mineralogia predominante desses solos é caulinítica e oxídica de baixa atividade, o teor de MO tem importância capital quando se pretende avaliar a qualidade do solo. Essa importância está ligada ao fornecimento de nutrientes, já que a MO pode ser responsável por, pelo menos, 56\% CTC destes solos (RAIJ, 1987), e na melhoria das propriedades físicas (agregação, estruturação - dinâmica da água) do solo. Além disso, sabe-se que a redução da matéria orgânica pode elevar a atividade do alumínio na solução do solo, resultando num ambiente hostil para as plantas, pois, quando ocorre a formação de complexos organo-mineral em presença de $\mathrm{MO}$, essa passa 
a controlar a atividade do alumínio na solução do solo e também do alumínio trocável de forma que o alumínio complexado perde seu caráter tóxico para as plantas (SIQUEIRA, 1986). Segundo Schaefer et al. (2002) a degradação do solo, a baixa produção de matéria seca e a degradação das pastagens ocorrem proporcionalmente com a perda de matéria orgânica do solo.

Em relação à Ds, observa-se que nos dois manejos os valores estão bem acima da referência. Entretanto, Reinert, Reichert e Silva (2001), propõem como valores críticos Ds para solos com textura média (argila entre 200 e $550 \mathrm{~g} \mathrm{~kg}^{-1}$ ), como no caso do solo estudado onde teor de argila em todos os manejo estudados situa-se entre 340 e 370 $\mathrm{g} \mathrm{kg}^{-1}$, o valor de Ds $=1,55 \mathrm{~kg} \mathrm{dm}^{-3}$. Logo, concluise que os valores de Ds encontrados não estão indicando compactação, a qual poderia restringir o crescimento e o desenvolvimento do sistema radicular das plantas.

$\mathrm{O}$ valor da macroporosidade do manejo PQ abaixo do valor de referência é muito prejudicial, pois, indica a existência de condições desfavoráveis à difusão de oxigênio, a drenagem da água pluvial na superfície, o que favorece a erosão, e o desenvolvimento das plantas, pois, pode ocorrer um aumento da resistência do solo ao crescimento radicular, tornando a planta mais susceptível a déficits hídricos e com limitada capacidade de absorver nutrientes em camadas subsuperficiais.

De acordo com os resultados obtidos concluiuse que os valores de densidade do solo, matéria orgânica, capacidade de troca de cátions e macroporosidade não diferiram na camada de solo analisada $(0-10 \mathrm{~cm})$ nos dois manejos estudados. Os polígonos formados no gráfico radial, comparando a área referência com os dois manejos estudados, são de magnitude e formato diferentes ao formado pelos valores de referência, indicando que o manejo sem queimadas anuais deve ser melhorado em relação à densidade do solo; já o manejo com queimadas anuais deve ser melhorado em relação à densidade, matéria orgânica, capacidade de troca de cátions e macroporosidade do solo.

\section{Referências}

EMPRESA BRASILEIRA DE PESQUISA AGROPECUÁRIA-EMBRAPA. Manual de métodos de análise de solo. Rio de Janeiro: Ministério da Agricultura, 1997. $212 \mathrm{p}$.

COHRON, G. T. Forces causing soil compaction. In: BARNES, K. K.; CARLETON, W. M.; TAYLOR, H. M.; THROCKMORTON, R. I.; VANDER BERG, G. E. Compaction of agricultural soils. Beltsville, ASAE, 1972. p. 106-122.

COSTA, E. A.; GOEDERT, W. J.; SOUSA, D. M. G. Qualidade de solo submetido a sistemas de cultivo com preparo convencional e plantio direto. Pesquisa Agropecuária Brasileira, Brasília, v.41, n. 7, p. 11851191, 2006.

FERNANDEZ, I.; CABANEIRO, A.; CARBALLAS, T. Organic matter changes immediately after a wild-fire in Atlantic Forest soil and comparison with laboratory soil heating. Soil Biology \& Biochemistry, Oxford, v. 29, n. 1, p. 1-11, 1997.

FERREIRA, R. R. M.; TAVARES FILHO, J.; FERREIRA, V. M.; RALISCH, R. Estabilidade física de solo sob diferentes manejos de pastagem extensiva em Cambissolo. Semina: Ciências Agrárias, Londrina, v. 31, n. 3, p. 531-538, jul./set. 2010.

HERINGER, I.; JACQUES, A. V. A.; BISSANI, C. A.; TEDESCO, M. Características de um Latossolo Vermelho sob pastagem natural sujeita à ação prolongada do fogo e de práticas alternativas de manejo. Ciência Rural, Santa Maria, v. 32, n. 2, p. 309-314, 2002.

HORTA, I. de M. F. Levantamento dos solos e ocupação da superficie do Município de Nazareno, MG. 2006. Dissertação (Mestrado em nome da área) - Universidade Federal de Lavras, Lavras.

JACQUES, A. V. A. A queima das pastagens naturais efeitos sobre o solo e a vegetação. Ciência Rural, Santa Maria, v. 33, n. 1, p. 177-181, 2003.

NEVES, B. M. C.; MIRANDA, H. S. Temperatura do solo em um campo sujo de cerrado durante uma queimada prescrita. In: SIMPÓSIO SOBRE O CERRADO, 8., 1996, Brasília. Anais... Planaltina: EMBRAPA-CPAC, 1996. p. 396-399.

RAIJ, B. van. Avaliação da fertilidade do solo. Piracicaba: POTAFOS, 1987. 142 p. 
REINERT, D. J.; REICHERT, J. M.; SILVA, V. R. Propriedades físicas dos solos em sistemas de plantio direto irrigado. In: CARLESSO, R.; PETRY, M. T.; ROSA, G. M.; CERETTA, C. A. (Org.). Irrigação por aspersão no rio Grande do Sul. Santa Maria: Palloti, 2001. v. 1, p. 114-133.

SCHACHT, W. H.; STUBBENDIECK, T.; BRAGG, T. B.; SMART, A. J.; DORAN, J. W. Soil quality response of reestablished grasslands to mowing and burning. Journal of Range Management, Denver, v. 49, n. 5, p. 458-463, 1996.

SCHAEFER, C. E. R. D. D.; SILVA, K. W. N.; PAIVA, F. F.; PRUSKI, M. R.; ALBUQUERQUE FILHO, M. A. Perdas de solo, nutrientes, matéria orgânica e efeitos microestruturais em Argissolo Vermelho-Amarelo sob chuva simulada. Pesquisa Agropecuária Brasileira, Brasília, v. 37, n. 5, p. 669-678, 2002.

SIQUEIRA, C. Calagem para plantas forrageiras. In: SIMPÓSIO SOBRE CALAGEM E ADUBAÇÃO DE PASTAGENS, 1., 1985, Nova Odessa. Anais... Piracicaba: Associação Brasileira para Pesquisa da Potassa e do Fósforo, p. 77-91, 1986.

TAVARES FILHO, J.; FERREIRA, R. R. M.; FERREIRA, V. M. Fertilidade química de solo sob pastagens formadas com diferentes espécies nativas e com Brachiaria decumbens manejadas com queimadas anuais. Semina: Ciências Agrárias, Londrina, v. 32, p. 1771-1782, 2011. Suplemento 1. 